\title{
Development of a Rapid Screening Method for Selection Against High Temperature Susceptibility in Garden Roses
}

\author{
Ockert Greyvenstein and Terri Starman ${ }^{1}$ \\ Department of Horticultural Science, Texas A\&M University, 2133 TAMU, \\ College Station, TX 77843
}

\section{Brent Pemberton \\ Texas A\&M AgriLife Research and Extension Center, P.O. Box 200, Overton, $T X 75684$}

\section{Genhua Niu}

Department of Horticultural Science, Agricultural Research and Extension Center at El Paso, 1380 A\&M Circle, El Paso, TX 79927

\section{David Byrne \\ Department of Horticultural Science, Texas A\&M University, 2133 TAMU, College Station, TX 77843}

Additional index words. heat stress, phenotyping, rose breeding, electrolyte leakage, chlorophyll fluorescence, power

\begin{abstract}
The decline of garden rose sales over the past 20 years can be partially attributed to the lack of material adapted to a wide range of landscapes, which includes adaptation to high temperature stress. Current methods for evaluating high temperature susceptibility in garden roses are based on field observations, which are time consuming and subjected to ever-changing environmental conditions. A series of experiments were conducted to optimize protocols and compare the use of chlorophyll fluorescence (CFL) and cell membrane thermostability (MTS) by way of electrolyte leakage as methods to screen for high temperature susceptibility. Immature leaves proved better than mature leaves for both CFL and MTS measurements, using either detached leaf or whole plant stress assays. MTS measured on immature leaves stressed in a water bath at $50{ }^{\circ} \mathrm{C}$ for 45 minutes proved most consistent in separating rose clones based on high temperature susceptibility. Stressing actively growing plants with flower buds of $2 \mathbf{~ m m}$ in diameter in a heat chamber at $44{ }^{\circ} \mathrm{C}$ for 3 hours resulted in increased flower abscission and leaf necrotic lesions on more susceptible clones when compared with those that were heat tolerant. Combining MTS measurements from immature leaves stressed in a water bath with the flower abscission and leaf necrosis responses $\mathbf{1 0}$ days after stress in a heat chamber could be the first step to screen and select against the more susceptible clones in a garden rose breeding program. Power analyses suggest that the proposed MTS protocol would be efficient in detecting differences between clones when the difference in electrolyte leakage is greater than $10 \%$.
\end{abstract}

Overall sales of garden roses have been declining over the past 20 years in the United States due, in part, to the lack of widely adapted cultivars to heat, drought, and salt stress in landscape environments (Byrne et al., 2010). Conversely, an increase in sales of shrub-type rose cultivars e.g., (Rosa $\times$ hybrida L.) Knock Out ${ }^{\circledR}$ rose 'RADrazz', which are widely adapted to abiotic stress conditions and biotic stress such as black spot (Diplocarpon rosae Wolf), has occurred (Hutton, 2012).

High temperature stress is a major limiting factor to growing agronomic and horticultural

Received for publication 9 July 2015. Accepted for publication 30 Oct. 2015

${ }^{1}$ Corresponding author. E-mail: tstarman@tamu. edu.
Currently, no method, apart from field observations, has been developed for phenotyping high temperature susceptibility in garden roses. At the Texas A\&M Rose Breeding Program, landscape performance was quantified on a $1-5$ scale. Landscape performance was influenced by the ability of the rose to maintain healthy foliage and perpetual flowering (Aggie Horticulture, 2014).

High temperature susceptibility of plants has been a topic of research as early as the 19th century. Sachs (1864) stressed leaves of various plants in a water bath followed by scoring the extent of necrotic lesions in the days to follow. The photosynthetic apparatus in plants is sensitive to temperature (Berry and Björkman, 1980). High temperature stress in plants is associated with reductions in photosynthetic activities and has been verified for some members of the Rosaceae, including red raspberry (Rubus idaeus L.), by recording the net photosynthetic rate of leaves at different temperatures (Fernandez and Pritts, 1994). Chlorophyll fluorescence is a nonintrusive measurement (Krause and Weis, 1991) used as a physiological parameter, which correlates with thermal tolerance to both high (Camejo et al., 2005; Weng and Lai, 2005; Yamada et al., 1996) and low temperatures (Stoddard et al., 2006)

When light energy enters the cell, and drives photochemistry, it is dissipated as heat, or is reemitted as fluorescence. Chlorophyll fluorescence is usually measured as the ratio of variable fluorescence $\left(F_{\mathrm{v}}\right)$ to maximum fluorescence $\left(F_{\mathrm{m}}\right)$ (Krause and Weis, 1991). Dark fluorescence $\left(F_{0}\right)$ is the fluorescence emitted when all the reaction centers in photosystem II are open. $F_{\mathrm{m}}$ is the fluorescence emitted when all the reaction centers in photosystem II are closed. $F_{\mathrm{v}}$ is the maximum variable fluorescence $\left(F_{\mathrm{v}}=F_{\mathrm{m}}-F_{0}\right)$ (Krause and Weis, 1991). The ratio of $F_{\mathrm{v}}$ over $F_{\mathrm{m}}$ is expected to decrease under high temperature stress conditions. The nonintrusive method of measuring CFL makes it a desirable approach to screen large numbers of individuals within breeding populations (Srinivasan et al., 1996)

Bilger et al. (1984) reported a significant correlation $(r=0.87)$ between the temperature resulting in 50\% necrosis and the temperature at which $F_{0}$ starts to increase. To our knowledge, CFL has not been investigated for high temperature tolerance in roses; however, CFL measured on detached leaves has been successfully used as an indicator of low temperature tolerance among 13 rose genotypes. The slope of $F_{\mathrm{v}}$ reduction among different genotypes accurately grouped genotypes as very resistant, resistant, or sensitive (Hakam et al., 2000). These $F_{\mathrm{v}}$ groupings correlated with previously reported visual scores of necrosis because of chilling injury $(\mathrm{CI})$.

High temperature injury can result in heat-induced loss of the semipermeability of the plasma membrane, the tonoplast, or other membranes within the cell (Berry and Björkman, 1980). Cell MTS makes use of a conductivity test to measure the amount of electrolyte leakage from leaf disks. Cell membrane thermostability has been successfully 
used as an indicator of high temperature tolerance on field crops such as wheat (Triticum aestivum L.) (Ibrahim and Quick, 2001a), 20 different species of vegetables (Kuo et al., 1993), tomato (Solanum lycopersicum L.) (Camejo et al., 2005), food legumes (Srinivasan et al., 1996) including cowpeas (Vigna unguiculata L.) (Thiaw and Hall, 2004), and ornamental plants such as chrysanthemum [Dendranthema $\times$ grandiflora (Ramat.) Kitam.] (Wang et al., 2008; Yeh and Lin, 2003).

Srinivasan et al. (1996) compared CFL and MTS as methods for phenotyping high temperature tolerance on four different food legumes previously characterized for high temperature tolerance and found both methods to be successful, with the correlation between CFL and MTS ranging between 0.57 and 0.87 . Both CFL and MTS were successful in distinguishing between a high temperature tolerant and susceptible tomato line (Camejo et al., 2005). The variables typically employed in evaluating either CFL or MTS as indicators of stress tolerance for various crops are usually based on stress temperature, duration, and the age of plant tissue. These variables, in combination with sound experimental design, must be optimized for each crop and technique before they can be applied effectively.

Currently, no rapid laboratory screening method has been developed for phenotyping high temperature susceptibility in garden roses. The objectives of the study described herein were to develop a rapid screening technique for phenotyping high temperature susceptibility in garden roses and to compare the efficacy of CFL and MTS as indicators of high temperature tolerance. A protocol for rapid screening is presented as well as guidelines on the power of experiments applying the proposed protocol.

\section{Materials and Methods}

Plant material. A series of experiments were conducted over a 3-year period beginning Apr. 2010 and ending Dec. 2012. Both commercial cultivars and breeding lines (referred to as clones from here forward) of garden roses and both field- and greenhousegrown plants were used. Field-grown plants were well established and maintained under ambient conditions on the Texas A\&M University Horticulture Research Farm in College Station, TX, or in raised beds in a trial rose garden on campus.

The Texas A\&M Rose Breeding Program continuously evaluates the performance of numerous rose clones. The clones used in this study were given a summer landscape performance rating between 2009 and 2011 (Table 1). All the clones used in this study were not present in a single field in the same years. The clones used were chosen as they represented a perceived range of summer performance and presumably heat tolerance.

Greenhouse-grown plants were kept at temperature set points $25 / 20{ }^{\circ} \mathrm{C}$ day/night. Temperatures occasionally reached $34{ }^{\circ} \mathrm{C}$ during hot summer days. Temperature was controlled by a pad and fan cooling system

Table 1. Description of rose clones used in this study with summer landscape rating based on performance during 2009-11. z

\begin{tabular}{|c|c|c|c|}
\hline Clone & Abbreviation & Brief description & $\begin{array}{l}\text { TAMU' summer } \\
\text { landscape rating }\end{array}$ \\
\hline 'Belinda's Dream' & $\mathrm{BD}$ & $\begin{array}{l}\text { Medium shrub with large very double flowers. } \\
\text { Carries Earth-Kind }{ }^{\circledR} \times \text { designation. }\end{array}$ & Good \\
\hline 'Basye's Blueberry' & $\mathrm{BB}$ & $\begin{array}{l}\text { Completely prickle free shrub with large } \\
\text { double to semidouble pink flowers. }\end{array}$ & Fair \\
\hline 'Caldwell Pink' & $\mathrm{CP}$ & $\begin{array}{l}\text { Small shrub with small lilac pink double flowers. } \\
\text { Carries Earth-Kind }{ }^{\circledR} \text { designation. }\end{array}$ & Excellent \\
\hline 'Marie Pavié' & MP & $\begin{array}{l}\text { Dwarf shrub with very light pink medium-sized } \\
\text { double flowers. }\end{array}$ & Good \\
\hline 'Old Blush' & OB & $\begin{array}{l}\text { Shrub with medium-sized pink semidouble to } \\
\text { double flowers. }\end{array}$ & Fair \\
\hline J06A & J06A & $\begin{array}{l}\text { Compact shrub with small- to medium-sized } \\
\text { white single flowers. Breeding line at TAMU. }\end{array}$ & Excellent \\
\hline J06B & J06B & $\begin{array}{l}\text { Compact shrub with small- to medium-sized } \\
\text { white single flowers. Breeding line at TAMU. }\end{array}$ & Excellent \\
\hline 'Sweet Chariot' & $\mathrm{SC}$ & $\begin{array}{l}\text { Small shrub with very fragrant highly double } \\
\text { small flowers. }\end{array}$ & Poor \\
\hline 'Vineyard Song' & VS & $\begin{array}{l}\text { Small shrub with fragrant highly double small } \\
\text { flowers. }\end{array}$ & Poor \\
\hline 'RADrazz' & $\mathrm{KO}$ & $\begin{array}{l}\text { The Knock Out }{ }^{\circledR} \text { rose. Medium shrub with } \\
\text { medium-sized single to semidouble deep pink } \\
\text { flowers. Carries Earth-Kind }{ }^{\circledR} \text { designation. }\end{array}$ & Excellent \\
\hline 'Sir Thomas Lipton' & SL & $\begin{array}{l}\text { Rugosa type shrub rose with medium-sized } \\
\text { double white flowers. }\end{array}$ & Poor \\
\hline
\end{tabular}

${ }^{\mathrm{z} N o t}$ all clones were present in a single field at the same time, rating present the perceived summer performance.

${ }^{\mathrm{y}}$ Ratings based on field observations during $2009-11$ by Texas A\&M Rose breeding program at College Station, TX.

${ }^{\mathrm{x}}$ Earth-Kind ${ }^{\circledR}$ designation indicates good landscape performance under a wide range of conditions (Aggie Horticulture, 2013).

in the summer months and by natural gas heaters in the winter months. All greenhouse plants were grown in a bark-based, soilless media (Fafard 52 Mix; Conard Fafard Inc., Agawam, MA)

Greenhouse plants were either obtained from The Antique Rose Emporium, Inc., Brenham, TX, as well-established plants in 7.8-L plastic pots or propagated from stem cuttings. Stem cuttings were two-node vegetative cuttings from recently flowered shoots. The basal end of each cutting was dipped in Rootech Cloning Gel $^{\mathrm{TM}}$ (Technaflora Plant Products Ltd., Mission, British Colombia, Canada), and rooted under mist using 1 perlite : 1 Fafard 52 potting mix for support. Frequency and duration of misting were adjusted depending on ambient conditions. Once rooted, cuttings were potted into $1.8-\mathrm{L}$ pots and later transplanted into 7.8-L plastic pots. The plants were irrigated and fertilized with each irrigation as required with $200 \mathrm{mg} \cdot \mathrm{L}^{-1} 20 \mathrm{~N}-3.4 \mathrm{P}-16.6 \mathrm{~K}$ liquid fertilizer (Peters ${ }^{\circledR}$ Professional 20-10-20, Everris, NA) except during the months of December to February when $200 \mathrm{mg} \cdot \mathrm{L}^{-1}$ 15N-5.4P-14.1 K (Peters ${ }^{\circledR}$ Professional 1516-17) was used. Periodically and especially in warmer months, $5.15 \mathrm{~g} \cdot \mathrm{L}^{-1}$ Sequestrene 138 (6\% iron chelate) (Becker Underwood, Inc., Ames, IA) was applied as a drench to prevent iron deficiency.

Detached leaf stress conditions. When detached leaves were used for CFL and MTS experiments, they were either the most recently fully expanded five-leaflet leaves (mature) or unfolded leaves (immature) directly below the first folded leaf on actively growing shoots. To avoid diurnal effects, all leaves were sampled in the mornings before $1000_{\mathrm{HR}}$ and placed in small, sealable clear plastic bags with a moist paper towel (to maintain high humidity), with the majority of the air vacuumed out.

For CFL measurements, the leaves were subjected to high temperature stress in a water bath set at $50{ }^{\circ} \mathrm{C} \pm 1{ }^{\circ} \mathrm{C}$, while remaining in the plastic bags. CFL measurements were recorded with a HANDY-PEA, CFL system (Hansatech Instruments Ltd., Norfolk, UK). Prior experimentation verified a 30-min dark adaptation period at ambient temperature, and a 1-s saturation pulse with a light intensity $2000 \mu \mathrm{mol} \cdot \mathrm{m}^{-2} \cdot \mathrm{s}^{-1}$ was optimal for recording CFL on garden roses. The fluorescence measurements $F_{0}$ and $F_{\mathrm{m}}$ were recorded from where $F_{\mathrm{v}} / F_{\mathrm{m}}$ was calculated. CFL was recorded $30 \mathrm{~min}$ post stress treatments.

Where possible, both CFL and MTS were recorded on the same leaves to allow for direct comparison of the methods. The MTS protocol was performed in $25 \mathrm{~mm} \times 95 \mathrm{~mm}$ flat-bottom glass culture tubes. Preliminary experimentation verified that ten to fifteen 5 -mm leaf strips in $10 \mathrm{~mL}$ of distilled water was optimum for MTS measurements of roses. Leaflets were cut into $5-\mathrm{mm}$ strips. Leaflets wider than $15 \mathrm{~mm}$ were cut along the midrib and subsequently cut into $5-\mathrm{mm}$ strips. Leaf strips were then washed and rinsed three times with distilled water. Leaf strips from leaves where CFL were not recorded were subjected to high temperature stress treatments in a water bath set at $50{ }^{\circ} \mathrm{C} \pm$ $1{ }^{\circ} \mathrm{C}$. The culture tubes containing the leaf strips were then placed in a water bath set at $25{ }^{\circ} \mathrm{C}$ for $5 \mathrm{~min}$ and then moved to a rotary shaker $(60 \mathrm{rpm})$ at room temperature for $24 \mathrm{~h}$, after which the first of two conductivity 
readings (EC1) were recorded. To release total electrolytes the tubes were autoclaved for $20 \mathrm{~min}\left(121{ }^{\circ} \mathrm{C}, 1.2 \mathrm{~kg} \cdot \mathrm{cm}^{-2}\right)$. When cooled to $25{ }^{\circ} \mathrm{C}$, the second conductivity reading (EC2) was taken. MTS was expressed as the reciprocal of relative leakage: MTS $=(1-\mathrm{EC} 1 / \mathrm{EC} 2)$ (Ibrahim and Quick, 2001b). Electric conductivity was measured by vortexing the test tubes for $1 \mathrm{~s}$ and pipetting $60 \mu \mathrm{L}$ onto a Horiba B-173 Compact Conductivity Meter (Horiba Ltd., Edison, NJ). The average of three measurements was recorded per sample. Unless otherwise stated, experiments were conducted using a randomized complete block design.

Whole plant stress conditions. High temperature stress treatments were conducted on whole plants in a greenhouse during the summer of 2011. Stress treatments consisted of shutting off the pad and fan cooling system and opening the shade in the greenhouses until temperatures reached $45{ }^{\circ} \mathrm{C}$, liquid in glass thermometer (SP Scienceware, Wayne, $\mathrm{NJ}$ ), and then placing plants in the greenhouse for various durations. Bench temperatures and relative humidity $(\mathrm{RH})$ in the greenhouse were logged with WatchDog A150 loggers (Spectrum Technologies, Plainfield, IL). Temperatures reached as high as $53{ }^{\circ} \mathrm{C}$ and had a mean of $51{ }^{\circ} \mathrm{C}$ during stress treatments with mean RH of $31 \%$. The maximum temperature recorded in the control greenhouse was $36^{\circ} \mathrm{C}$ and the mean temperature during the course of the experiment was $33{ }^{\circ} \mathrm{C}$ with $43 \%$ mean RH. Photosynthetically active radiation $(P A R)$ was measured using a LightScout Quantum Light Sensor 3668I (Spectrum Technologies), the average $P A R$ in the stress greenhouse was $890 \mu \mathrm{mol} \cdot \mathrm{m}^{-2} \cdot \mathrm{s}^{-1}$ compared with $301 \mu \mathrm{mol} \cdot \mathrm{m}^{-2} \cdot \mathrm{s}^{-1}$ in the control greenhouse. The maximum $P A R$ recorded during the stress period was $1531 \cdot \mu \mathrm{mol} \cdot \mathrm{m}^{-2} \cdot \mathrm{s}^{-1} \mathrm{com}-$ pared with the maximum $P A R$ for control conditions of $424 \mu \mathrm{mol} \cdot \mathrm{m}^{-2} \cdot \mathrm{s}^{-1}$.

Subsequently, to enable year-round whole plant stress treatments, a high temperature stress chamber was constructed by converting a $2.13 \mathrm{~m} \times 2.74 \mathrm{~m} \times 2.00 \mathrm{~m}(\mathrm{~L} \times \mathrm{W} \times \mathrm{H})$ walk-in refrigerator with a time controller for lights, an environmental controller, heating element, and humidifier. Fans were installed for air circulation. The heat chamber construction allowed for the control of temperature within the range 20 to $50{ }^{\circ} \mathrm{C} \pm 1{ }^{\circ} \mathrm{C}$, and $\mathrm{RH}$ within the range $10 \%$ to $60 \% \pm 3 \%$. Both fluorescent and incandescent bulbs were used as light sources and resulted in $P A R$ of $25 \mu \mathrm{mol} \cdot \mathrm{m}^{-2} \cdot \mathrm{s}^{-1}$ at plant canopy level, measured with a ceptometer (Accupar LP-80; Decagon Devices, Inc., Pullman, WA).

Power and sample size. Calculations were based on the smallest significant differences $(\delta)$ in MTS detected between clones when immature leaves were stressed in a water bath. The residual and variance $\left(\sigma^{2}-\right.$ statistical analysis below) of five detached leaf experiments using the suggested protocol (results of all experiments not presented) was averaged. The resulting mean residual standard deviation $(\sigma)$ of 0.0483 was used in power calculations. Similarly, the mean block variance $\left(\sigma_{\mathrm{B}}^{2}\right)$ resulted in a block standard deviation $\left(\sigma_{\mathrm{B}}\right)$ of 0.0873 used in power calculations. Power calculations were performed for randomized complete block designs comparing 2, 4, 8, or 20 clones with the number of blocks ranging from 2 to 20 . The significance level $(\alpha)$ was set at 0.05 . Power analyses were performed to detect differences in MTS of $0.05,0.1$, and 0.2 between clones. Power analyses were adjusted with Tukey's adjustment for multiple error testing. All power analyses were performed using Piface software (Lenth, 2006).

Statistical analysis. All statistical analyses were performed using JMP (version 9.0; SAS Institute Inc., Cary, NC 1989-2010). Randomized complete block layouts with subsampling were analyzed by fitting a mixed least squares model. Experiments with repeated measurements on the same plants were analyzed by averaging over the subsamples and fitting a univariate repeated measures model. The unbalanced experiment (experiment 4) was analyzed by fitting a mixed least squares model. The random effect of individual plants was included in the repeated measures and models where the design was unbalanced. Differences among fixed effects were investigated by Student's $t$ test pairwise comparisons and Tukey's honestly significant difference tests. Linear contrasts were performed to investigate significant two-way interaction effects. The Pearson's correlation coefficient was calculated to evaluate the relationship between CFL and MTS where applicable. Nominal logistic regression was performed on binomial data and differences were evaluated based on odds ratios.

\section{Results}

Experiment 1: Preliminary investigation to detect differences between clones. Clones 'Belinda's Dream' (BD), 'Basye's Blueberry' (BB), 'Caldwell Pink' (CP), 'Marie Pavié' (MP), and 'Old Blush' (OB) (Table 1) replicated in four separate beds in the trial garden were used for this experiment. Two mature leaves (subsamples) were harvested from each replicate of all clones. CFL was recorded before stress treatment and no differences were detected with the overall mean $F_{\mathrm{v}} / F_{\mathrm{m}}$ for the five clones being 0.83 . Then leaves were stressed in a water bath at $50{ }^{\circ} \mathrm{C} \pm 1{ }^{\circ} \mathrm{C}$ for $60 \mathrm{~min}$ (Kuo et al., 1993), followed by CFL measurement $30 \mathrm{~min}$ post stress. No significant differences in CFL post stress was detected among clones, with the overall mean $F_{\mathrm{v}} / F_{\mathrm{m}}$ being 0.33 . Although not statistically significant the clones with the greatest difference in CFL were $\mathrm{BB}$ and BD (0.20).

To optimize duration of water bath high temperature stress $\left(50{ }^{\circ} \mathrm{C} \pm 1{ }^{\circ} \mathrm{C}\right)$, six mature leaves (subsamples) from three plants (replicates) of field-grown $\mathrm{BB}$ and $\mathrm{BD}$ were harvested and three stress duration treatments $(15,30$, or $60 \mathrm{~min})$ were followed by CFL measurements. BD had a greater $F_{\mathrm{v}} / F_{\mathrm{m}}$ than
$\mathrm{BB}$ at all three durations (Fig. 1). The greatest difference $(0.32)$ between $\mathrm{BB}$ and $\mathrm{BD}$ was observed after $30 \mathrm{~min}$ of stress. It was concluded that a stress duration of between $30 \mathrm{~min}$ and $60 \mathrm{~min}$ (45 min) would be used for future experiments to achieve maximum separation between clones.

To compare efficacy of CFL vs. MTS, eight mature leaves (subsamples) from two plants (replicates) of field-grown plants from J06A (breeding clone) and 'Vineyard Song' (VS) were subjected to 45-min stress in a water bath set at $50{ }^{\circ} \mathrm{C}$, which revealed no differences between clones using CFL (Fig. 2A) pre-and poststress treatment. Then leaves were prepared for MTS measurements which resulted in VS having the greatest amount of electrolyte leakage (Fig. 2B). The MTS result was in accordance to landscape performance as VS has appeared more susceptible to high temperatures in field evaluations (Table 1).

Experiment 2: Improving resolution with clone selection, heat source, detached versus whole plant, and leaf developmental stage. A lack of differences in CFL among clones in the first experiment may have been due to clones having similar summer landscape performance. It was concluded that a more diverse set of clones be used going forward. Accordingly, CFL were recorded and compared among clones: BD, Knock Out ${ }^{\circledR}$ rose 'RADrazz' (KO), and 'Sir Thomas Lipton' (SL) (Table 1). Measurements were taken on two mature leaves (subsamples) stressed in a water bath for $45 \mathrm{~min}$ from five plants (replicates) grown in 7.8-L pots. No differences in CFL were detected among the clones even though $\mathrm{KO}$ had superior landscape performance in north-central Texas over BD and SL (Mackay et al., 2008).

The inability to detect differences in CFL based on detached leaf assays prompted whole plant stress assays. Four plants (replicates) of the same three clones (BD, KO, and $\mathrm{SL})$ grown in 7.8-L pots were subjected to control or high temperature stress conditions in the greenhouse. Control plants were kept under ambient conditions and plants to be

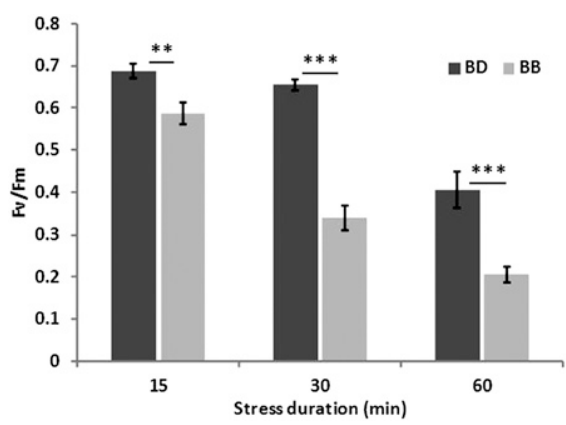

Fig. 1. Chlorophyll fluorescence measured as the ratio of variable fluorescence $\left(F_{\mathrm{v}}\right)$ over maximum fluorescence $\left(F_{\mathrm{m}}\right)$ on detached mature leaves of 'Basye's Blueberry' (BB) and 'Belinda's Dream' (BD) over three durations of high temperature stress in a water bath $\left(50^{\circ} \mathrm{C}\right)$. Error bars indicate $1 \mathrm{SE} . * *, * * *$ Indicate significance of linear contrasts between clones for each stress duration at $\alpha \leq 0.01$ and 0.001 . 
heat stressed were moved to the adjacent greenhouse where stress conditions were imposed. CFL measurements were recorded before stress conditions and then hourly for three hours on two mature leaves (subsamples) per plant. Plants were allowed to recover overnight and CFL was recorded on the same leaves again at $0920 \mathrm{HR}$ the following morning. CFL measurements from different subsamples were averaged over individual plants.

CFL measurements resulted in significant time, treatment, and treatment $\times$ time effects (Table 2). No change in CFL over time occurred for plants in the control greenhouse (Fig. 3). All the plants subjected to stress in the greenhouse had a significant reduction in CFL and did not recover completely after an overnight period (Fig. 3). During this experiment it was observed that immature leaves on all three clones showed visible signs of stress such as wilting.

Subsequently, CFL was recorded on immature leaves of $\mathrm{BD}, \mathrm{KO}$, and SL grown in 7.8-L pots. Eight (replicates) plants were subjected to $110 \mathrm{~min}$ of stress conditions in the greenhouse. CFL was recorded on one immature leaf per plant before the onset of stress, $40 \mathrm{~min}, 110 \mathrm{~min}, 170 \mathrm{~min}$, and at $0920_{\mathrm{HR}}$ the following morning after plants had time to recover.

No differences in CFL were detected on immature leaves before the onset of stress. CFL of immature leaves from plants subjected to stress under greenhouse conditions resulted in significant: clone, time, and clone $\times$ time effects (Table 2). After $110 \mathrm{~min}$, all the immature leaves started to show signs of wilting, making CFL measurements challenging. All clones showed a reduction in CFL during stress conditions and BD had the greatest reduction (Fig. 4). At no time was CFL different between KO and SL. The overnight recovery period allowed leaves of $\mathrm{KO}$ and SL to fully recover, whereas BD leaves did not show any recovery. The lack of recovery in CFL points toward permanent injury of the photosynthetic apparatus in BD leaves (Fig. 4).

Experiment 3: Optimization of duration of heat chamber treatment. Because the greenhouse was not deemed a year-round way to impose heat treatments, a heat chamber was constructed. In this experiment it was determined whether 3 or $5 \mathrm{~h}$ of high temperature stress was sufficient for detecting differences between clones with known differences in summer landscape performance. Four plants (replicates) in 1.8-L containers from clones J06A, VS, and SL were stressed in the heat chamber set at $42{ }^{\circ} \mathrm{C}$ and $35 \% \mathrm{RH}$ for 3 or $5 \mathrm{~h}$ for a total of 24 plants. The plants were moved from the greenhouse at $0800 \mathrm{HR}$ and two immature leaves (subsamples) on each plant were labeled. CFL was measured on each leaf before placing in the heat chamber. All labeled leaves were detached immediately after the stress treatment and processed for CFL and MTS measurements on the same leaves.

No differences in CFL (0.81) were detected among clones before the heat chamber treatments, or after the 3-h treatment (Fig. 5A). The 5-h treatment resulted in a decrease in
A

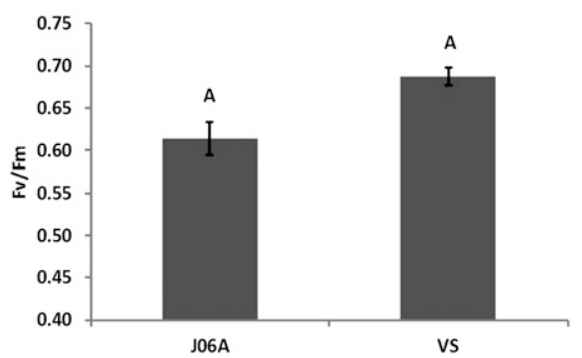

B

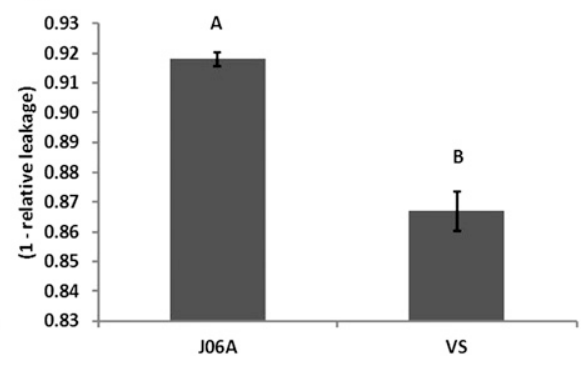

Fig. 2. Chlorophyll fluorescence measured as the ratio of variable fluorescence $\left(F_{\mathrm{v}}\right)$ over maximum fluorescence $\left(F_{\mathrm{m}}\right)(\mathbf{A})$ and cell membrane thermostability measured as 1 - relative electrolyte leakage (B) for rose clones 'Vineyard Song' (VS) and J06A using mature, detached leaves subjected to high temperature stress in a water bath $\left(50^{\circ} \mathrm{C}\right.$ for $\left.45 \mathrm{~min}\right)$. Error bars represent $1 \mathrm{SE}$. Clones not connected by the same letter are significantly different, $\alpha \leq 0.05$.

Table 2. F ratio tests of fixed effects on chlorophyll fluorescence measured on mature and immature leaves of whole plants subjected to high temperature stress in the greenhouse. Analyses were performed by fitting a univariate repeated measures model and included the individual plant as random effect.

\begin{tabular}{lcc}
\hline Source of variance & $\begin{array}{c}\text { Mature } \\
\text { leaves }\end{array}$ & $\begin{array}{c}\text { Immature } \\
\text { leaves }\end{array}$ \\
\hline Clone & $0.001 \mathrm{NS}$ & $16.371^{* * *}$ \\
Time & $22.048^{* * *}$ & $47.308^{* * *}$ \\
Clone $\times$ time & $1.077_{\mathrm{NS}}$ & $11.839^{* * *}$ \\
Treatment & $27.509 * * *$ & - \\
Clone $\times$ treatment & $0.172 \mathrm{NS}$ & - \\
Treatment $\times$ time & $21.956^{* * *}$ & - \\
\hline
\end{tabular}

NS, ***Nonsignificant and significant at $P$ value $<$ 0.001 .

CFL with SL being the least affected and VS the most. J06A was not different from either SL or VS (Fig. 5B). Both 3- and 5-h treatments resulted in MTS showing differences among clones (Fig. 5C and D). No stress duration or measurement resulted in separation between J06A and SL. The MTS results for both 3- and 5-h treatments corresponded with landscape ratings of J06A and VS (Table 1), where J06A performed better than VS in the field.

Experiment 4: Comparing efficacy between CFL and MTS, and differences on whole plant level after high temperature treatment. This experiment consisted of two phases, with the first directly comparing CFL and MTS, and the second evaluating differences in response to high temperature shock on a whole plant level between clones with observed differences in the landscape. Ten plants of J06A, J06B (breeding clones), 'Sweet Chariot' (SC), and VS were grown in 1.8 -L pots. When established, plants were cut back to stimulate and synchronize regrowth. Because of growth rates of the clones and available space in the heat chamber, the experiment was conducted in two groups: J06B with SC first and then J06A with VS. The first group was pruned $10 \mathrm{~d}$ before the second group.

When at least five immature leaves on seven plants (replicates) of J06B and SC were present, two immature leaves per plant (subsamples) were harvested and used in a detached leaf assay. Leaves were subjected to high temperature stress in a water bath $\left(50{ }^{\circ} \mathrm{C}\right.$ for $45 \mathrm{~min}$ ). CFL and MTS were recorded on

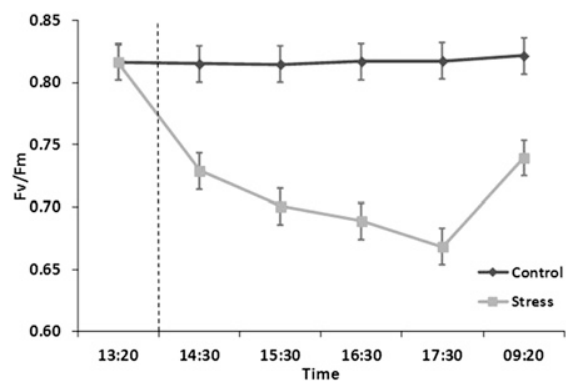

Fig. 3. Pooled chlorophyll fluorescence measured as the ratio of variable fluorescence $\left(F_{\mathrm{v}}\right)$ over maximum fluorescence $\left(F_{\mathrm{m}}\right)$ on rose clones 'Belinda's Dream', 'RADrazz', and 'Sir Thomas Lipton' using mature leaves on whole plants subjected to high temperature stress or control conditions in the greenhouse. Plants were moved to stress conditions at vertical line. The last measurement at $0920 \mathrm{HR}$ was recorded after plants had been allowed to recover overnight. Error bars represent $1 \mathrm{SE}$.

the same leaves. The following day two immature leaves (subsamples) on the same plants were labeled and the plants were subjected to high temperature stress in the heat chamber set at $44{ }^{\circ} \mathrm{C}$ with $50 \% \mathrm{RH}$ for $3 \mathrm{~h}$. After the stress treatment the plants were removed from the heat chamber and the labeled leaves were detached immediately and processed for CFL and MTS measurements. When seven plants from J06A and VS reached the correct stage of growth, they were subjected to the same experimental procedure as the first group.

CFL revealed a difference between clones of both groups when leaves were subjected to high temperature stress in the water bath, but not when plants were stressed in the heat chamber $\left(3 \mathrm{~h}, 44{ }^{\circ} \mathrm{C}\right.$, and $\left.50 \% \mathrm{RH}\right)$ (Table 3 ). MTS resulted in differences between clones of both groups when stress was applied in either the water bath or heat chamber (Table 3). All differences detected between clones corresponded to field performance with the two J06 lines having superior performance over SC and VS under high temperatures. A strong positive correlation $(r=0.74 * * *)$ was found between CFL and MTS across measurements taken on leaves stressed in the water bath. No correlation $\left(r=0.21^{\mathrm{NS}}\right)$ was found between CFL and 


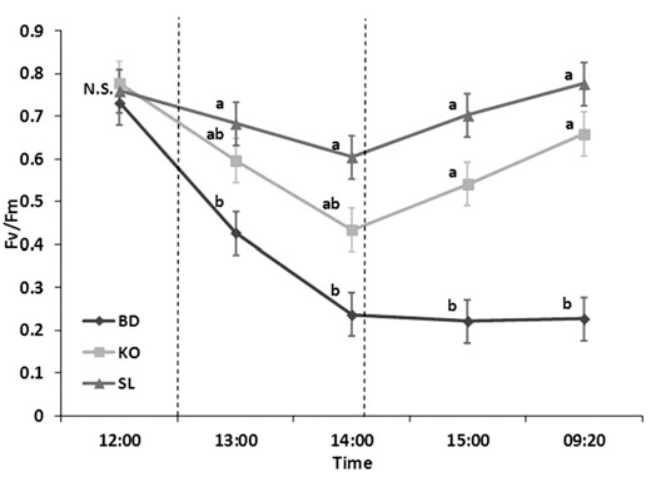

Fig. 4. Chlorophyll fluorescence measured as the ratio of variable fluorescence $\left(F_{\mathrm{v}}\right)$ over maximum fluorescence $\left(F_{\mathrm{m}}\right)$ using immature leaves of rose clones 'Belinda's Dream' (BD), 'RADrazz' (KO), and 'Sir Thomas Lipton' (SL) when whole plants were subjected to high temperature stress under greenhouse conditions. Error bars represent 1 SE. Differences among clones within time periods were evaluated by linear contrasts. Clones not connected by the same letter are significantly different, $\alpha \leq 0.05$. First vertical line indicates time point where all plants were moved into stress conditions, the second vertical line indicates the time point where plants were moved out of stress conditions. The time period 09:20 were taken the following morning after plants had time to recover overnight.
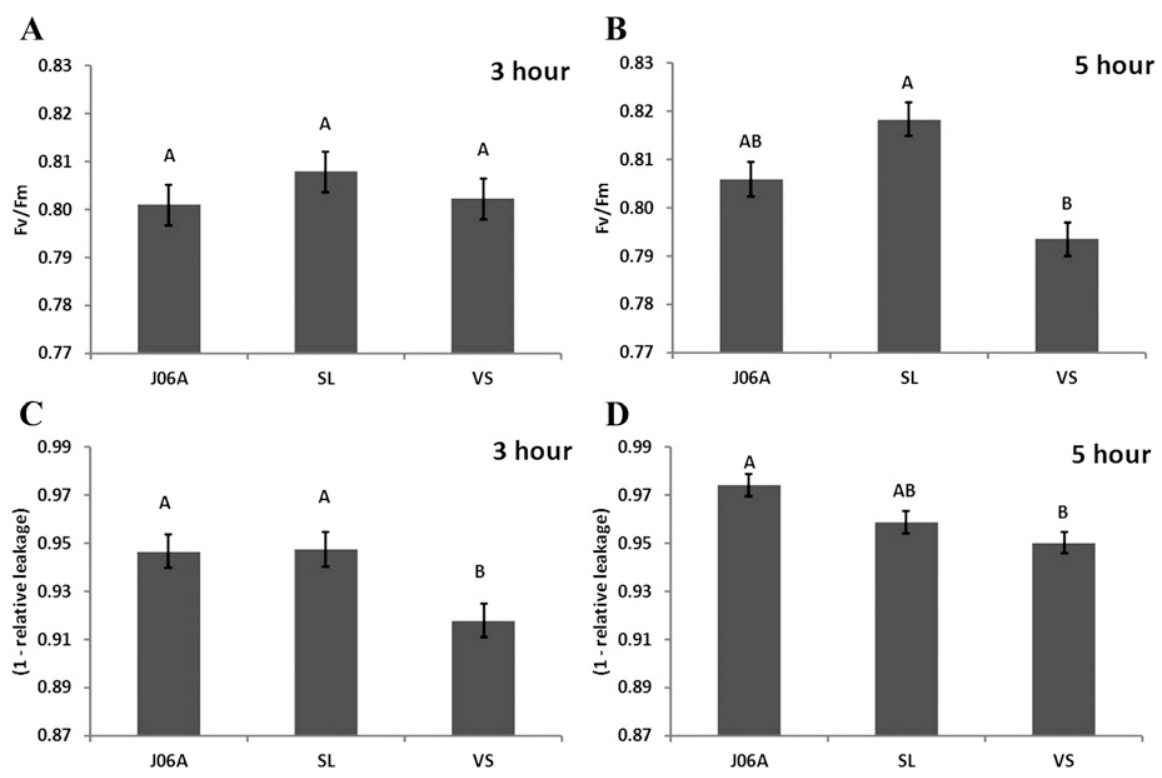

\section{D}

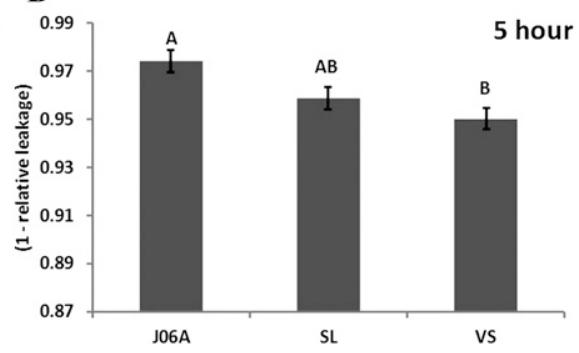

Fig. 5. Chlorophyll fluorescence measured as the ratio of variable fluorescence $\left(F_{\mathrm{v}}\right)$ over maximum fluorescence $\left(F_{\mathrm{m}}\right)(\mathbf{A}, \mathbf{B})$ compared with membrane thermostability measured as 1 - relative electrolyte leakage (C, D) measured on immature leaves of rose clones J06A, 'Sir Thomas Lipton' (SL), and 'Vineyard Song' (VS) subjected to high temperature stress in the heat chamber set at $42{ }^{\circ} \mathrm{C}$ and $35 \%$ $\mathrm{RH}$ for three $(\mathbf{A}, \mathbf{C})$ and five $(\mathbf{B}, \mathbf{D})$ hours. Error bars represent $1 \mathrm{sE}$. Clones not connected by the same letter are significantly different, $\alpha \leq 0.05$ with Tukey's adjustment.

Table 3. Chlorophyll fluorescence (CFL) and membrane thermostability (MTS) measured on immature leaves stressed in a water bath $\left(50{ }^{\circ} \mathrm{C}\right.$ for $\left.45 \mathrm{~min}\right)$ and heat chamber $\left(44{ }^{\circ} \mathrm{C}, 50 \% \mathrm{RH}\right.$ for $\left.3 \mathrm{~h}\right)$.

\begin{tabular}{|c|c|c|c|c|c|}
\hline & & \multicolumn{2}{|c|}{ Group $1^{\mathrm{z}}$} & \multicolumn{2}{|c|}{ Group 2} \\
\hline & & $\mathrm{J}_{06 \mathrm{~B}^{\mathrm{y}}}$ & $\mathrm{SC}$ & J06A & VS \\
\hline \multirow{3}{*}{ Water bath } & CFL & $0.44 \pm 0.018 \mathrm{a}^{\mathrm{x}}$ & $0.37 \pm 0.018 \mathrm{~b}$ & $0.39 \pm 0.052 \mathrm{a}$ & $0.21 \pm 0.052 \mathrm{~b}$ \\
\hline & MTS & $0.91 \pm 0.006 \mathrm{a}$ & $0.80 \pm 0.006 \mathrm{~b}$ & $0.63 \pm 0.032 \mathrm{a}$ & $0.54 \pm 0.032 b$ \\
\hline & CFL & $0.80 \pm 0.006 \mathrm{a}$ & $0.79 \pm 0.006 \mathrm{a}$ & $0.81 \pm 0.010 \mathrm{a}$ & $0.77 \pm 0.010 \mathrm{a}$ \\
\hline Heat chamber & MTS & $0.98 \pm 0.002 \mathrm{a}$ & $0.97 \pm 0.002 \mathrm{~b}$ & $0.98 \pm 0.002 \mathrm{a}$ & $0.96 \pm 0.002 \mathrm{~b}$ \\
\hline
\end{tabular}

${ }^{\mathrm{z}}$ Group1 includes J06B and SC, Group 2 includes J06A and VS.

y J06A and J06B: Breeding lines, SC: 'Sweet Chariot', VS: 'Vineyard Song'.

${ }^{\mathrm{x}}$ Comparisons made between clones within groups. Clones not connected by the same letter are significantly different, $\alpha<0.05$.

MTS measurements on leaves where plants were stressed in the heat chamber.

Following the heat chamber treatment, all J06B and SC plants were returned to normal greenhouse conditions. Three shoots with a terminal flower bud $\approx 1-2 \mathrm{~mm}$ in diameter were labeled for visual evaluation. Three shoots on three plants of J06B and SC that were not subjected to the heat chamber treatment were also labeled for comparison.

All plants were evaluated $10 \mathrm{~d}$ following the heat chamber treatment. The total number of shoots with at least one abscised flower and the number of shoots with no visible sign of flower abscission were recorded on each plant (Fig. 6A). The presence or absence of leaf necrosis was scored on the 10th day for each of the labeled shoots (Fig. 6B). On the day that the terminal flower of each of the labeled shoots was fully open, the flower was harvested by cutting at the base of the receptacle and the flowering date was recorded. The individual flowers were dried to a constant weight in a drying oven at $60^{\circ} \mathrm{C}$ and dry weights were recorded (Mettler AE 50; Mettler-Toledo International Inc., Columbus, $\mathrm{OH})$. In situations where the terminal flower abscised, weight was recorded as a zero.

None of the plants showed any visible signs of stress immediately post heat chamber treatment. Evaluations $10 \mathrm{~d}$ post heat chamber treatment revealed visible signs of high temperature damage such as shoot burn (Fig. 6C), flower abortion (Fig. 6A and D), and leaf necrosis (Fig. 6B).

The total number of shoots with and without aborted flowers $10 \mathrm{~d}$ post heat chamber treatment between J06B and SC resulted in a clone effect. Thirty-four percent (30/89) of J06B shoots had at least one aborted flower, whereas $55 \%(29 / 53)$ of SC shoots had at least one aborted flower. After adjusting for the replicate effect the odds of J06B not having aborted flowers was 1.63 times (95\% CI, 1.13-2.35) that of SC (likelihood ratio $\left.\chi^{2}=6.99^{* *}\right)$.

SC was more susceptible to leaf necrosis than J06B. After $10 \mathrm{~d}, 10 \%(1 / 21)$ of the labeled J06B shoots and $29 \%(6 / 21)$ of $\mathrm{SC}$ shoots showed signs of leaf necrosis. A significant clone effect was detected. The odds of J06B shoots not having leaf necrosis present was 2.84 times (95\% CI, 1.07-12.81) that of SC (likelihood ratio $\chi^{2}=4.41^{*}$ ).

For better comparison of J06B and SC, flower dry weight was analyzed as proportionate flower weight. Only treatment was significant $(P$ value $=0.016)$. Flowers from heat-stressed plants were reduced by $19 \%$. All flowers opened and were harvested between 14 and $25 \mathrm{~d}$ following the heat chamber treatment with the mean number of days to open flower being $18 \mathrm{~d}$. Adding days to flower as covariate did not change the outcome of the test. Although not significant, J06B and SC flowers were reduced by 10 and $29 \%$, respectively.

Experiment 5: Optimized rapid screening protocol. The final step in this project was to combine the optimized conditions from the previous experiments to evaluate differences in high temperature tolerance between J06B and VS. Ten well-established plants (replicates) in 1.8-L pots were used and plants were pruned to stimulate and synchronize regrowth. Two immature leaves (subsamples) from each plant were harvested and prepared for MTS measurements. The tubes containing the leaf strips were subjected to stress in a water bath $\left(50{ }^{\circ} \mathrm{C}\right.$ for $\left.45 \mathrm{~min}\right)$. 


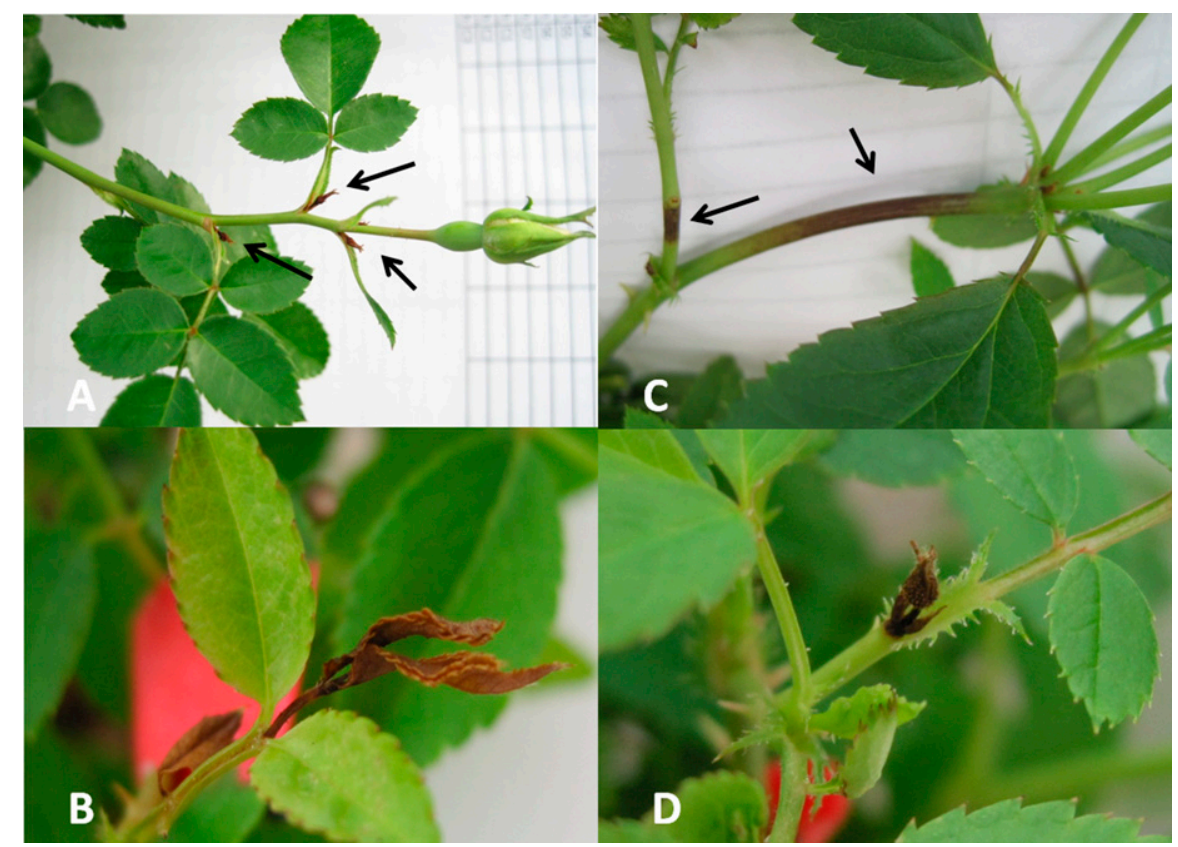

Fig. 6. Ten days post stress treatment in the heat chamber set at $44{ }^{\circ} \mathrm{C}$ and $50 \% \mathrm{RH}$, visual signs of high temperature stress was observed and recorded. Axial flower buds abscised (A), leaf necrosis was mostly limited to immature leaves $(\mathbf{B})$, shoot burn showing clear signs of browning $(\mathbf{C})$, and a number of terminal flowers abscised (D). Arrows indicate axial flower buds abscised (A) and browning on shoots (C).

Subjecting immature leaves from ten plants of J06B and VS to high temperature stress in the water bath resulted in a significant clone effect. In correspondence to previous results, J06B possessed greater membrane stability than VS after high temperature stress (Fig. 7).

Power and sample size. The significance of a statistical test $(\alpha)$ is the probability of making a type I error. The power of a test $(1-\beta)$ is the probability of detecting the smallest significant difference $(\delta)$, where $\beta$ is the probability of making a type II error. The power of a test can also be defined as: "the probability of obtaining a statistical significant result using a statistical test", and thus depends on $\delta, \alpha$, and sample size (Lenth, 2007). The power analyses predicted that immature detached leaves stressed in a water bath would not be very effective in detecting MTS differences of 0.05 between clones (Fig. 8A). To achieve a power of $0.8,17$ blocks (replicates) would be required to detect differences of 0.05 between two clones, which would not constitute a high throughput screening protocol. The proposed protocol is likely to be effective in detecting MTS differences of 0.1 and larger between clones (Fig. 8B and C). Using only 9 blocks one could achieve a reasonable power $(0.78)$ for detecting a 0.1 difference in MTS between 20 clones after adjusting for Tukey's multiple error testing (Fig. 8B).

\section{Discussion}

The ability to quantify high temperature stress and to rapidly screen garden rose cultivars for high temperature susceptibility was dependent on temperature and duration of treatment. By optimizing the stress duration, we maximized the difference in CFL between two clones with similar landscape performance ratings. Subjecting leaves to stress for $45 \mathrm{~min}$ at $50^{\circ} \mathrm{C}$ is similar to protocols used in other crops. Weng and Lai (2005) reported the temperature where $F_{0}$ starts to increase sharply for Rosa rugosa Thunb. ex Murray to be around $47^{\circ} \mathrm{C}$, although they made use of a 20-min incubation period, they placed leaves directly in the water bath and not in plastic bags as in our experiment. When investigating high temperature tolerance among 59 species of vegetables using electrolyte leakage Kuo et al. (1993) used an incubation period of $1 \mathrm{~h}$ and a stress temperature of $50{ }^{\circ} \mathrm{C}$, which was effective in separating differences.

The inability to detect differences among $\mathrm{BD}, \mathrm{KO}$, and SL based on detached leaves prompted whole plant stress assays. Although severe stress conditions were imposed on plants in the greenhouse, no difference among clones were detected when recording CFL on mature leaves. Conversely, CFL on immature leaves resulted in separation among clones. CFL recorded on mature leaves were successful in phenotyping an interspecific raspberry (Rubus) population (Bravo, 2009) and for $R$. rugosa (Weng and Lai, 2005), which is in contrast with the results presented.

Comparing CFL from immature leaves of $\mathrm{BD}, \mathrm{KO}$, and $\mathrm{SL}$ resulted in $\mathrm{BD}$ being the most susceptible and no difference between $\mathrm{KO}$ and SL. Immature leaves of BD were not able to recover to prestress $F_{\mathrm{v}} / F_{\mathrm{m}}$ levels after an overnight period similar to high temperature susceptible chickpeas (Cicer arietinum $\mathrm{L}$.) stressed at $50{ }^{\circ} \mathrm{C}$ for $4 \mathrm{~h}$ (Srinivasan et al., 1996). KO and SL did recover which was also reported for the more tolerant groundnuts (Arachis hypogaea L.) (Srinivasan et al., 1996).

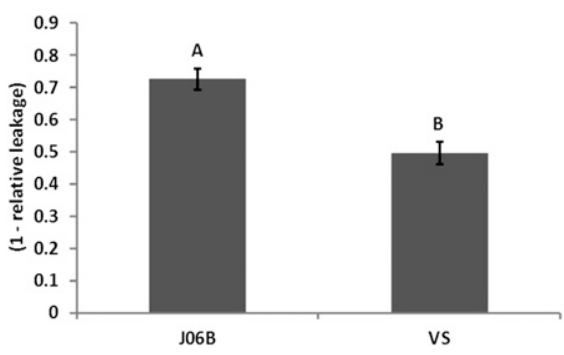

Fig. 7. Cell membrane thermostability measured as 1 - relative electrolyte leakage on immature leaves of J06B and 'Vineyard Song' (VS) stressed in a water bath for $45 \mathrm{~min}$ set at $50^{\circ} \mathrm{C}$. Error bars represent $1 \mathrm{SE}$. Clones not connected by the same letter are significantly different, $\alpha \leq 0.05$.

$\mathrm{KO}$ was expected to have the smallest decrease in CFL followed by BD and SL. On the basis of overall landscape performance and vigor (1-10 scale) under minimal input conditions in North Central Texas, KO performed better than both $\mathrm{BD}$ and $\mathrm{SL}$ $(\mathrm{KO}=9.2, \mathrm{BD}=6.1$, and $\mathrm{SL}=6.3)$ (Mackay et al., 2008). In terms of flowering percentage, BD $(10 \%)$ were more floriferous than SL (5\%) (Mackay et al., 2008). The lack of a difference in CFL between $\mathrm{KO}$ and SL was surprising. Vigor is highly influenced by black spot (D. rosae Wolf) (Mackay et al., 2008) and the low vigor and overall ratings received by SL could in part be due to susceptibility to black spot (HelpMeFind, 2012).

Thicker leaves have been associated with high temperature tolerance in Chinese cabbage (Brassica rapa subsp. pekinensis) (Kuo et al., 1988). SL is a $R$. rugosa hybrid displaying typical $R$. rugosa leaves which have been described as thick and leathery with pubescent abaxial and rugose adaxial surfaces (Bruun, 2005), all of which are traits associated with avoiding high temperature stress.

Subjecting plants to stress in the heat chamber resulted in MTS being useful for separating clones in accordance to field observations, whereas CFL failed. The inability of CFL to detect differences between clones subjected to stress in the heat chamber is in contrast to what was observed when stress was imposed under greenhouse conditions. Stress conditions in the greenhouse were more severe than those in the heat chamber, although stress duration was greater in the heat chamber. Temperatures in the greenhouse reached $50{ }^{\circ} \mathrm{C}$ whereas the heat chamber temperature was controlled at $42{ }^{\circ} \mathrm{C}$ or $44{ }^{\circ} \mathrm{C}$. Plants subjected to stress in the greenhouse experienced an average $P A R$ of $890 \mu \mathrm{mol} \cdot \mathrm{m}^{-2} \cdot \mathrm{s}^{-1}$, nearly 36 times that of the $P A R$ in the heat chamber $\left(25 \mu \mathrm{mol} \cdot \mathrm{m}^{-2} \cdot \mathrm{s}^{-1}\right)$. Sharp increases in light intensity will decrease $F_{\mathrm{v}} / F_{\mathrm{m}}$ (Björkman and Demmig, 1987), and the maximum $P A R$ experienced under greenhouse stress conditions was $1531 \mu \mathrm{mol} \cdot \mathrm{m}^{-2} \cdot \mathrm{s}^{-1}$. The differences in CFL detected among clones stressed in the greenhouse could be attributed to an additive effect of increased light intensity and higher temperatures than what was experienced in the heat chamber. 


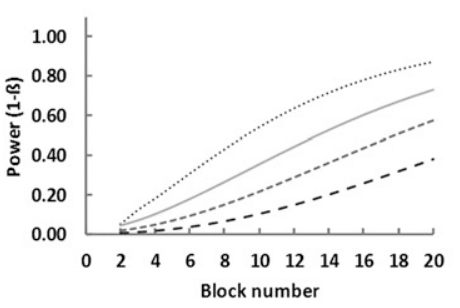

B

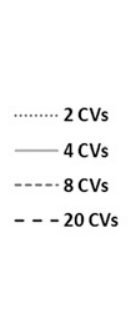

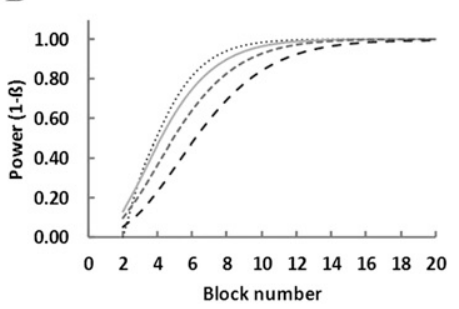

C

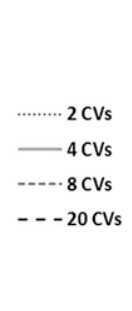

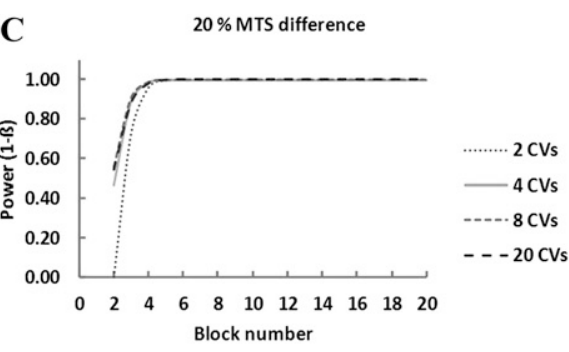

Fig. 8. Predicted power $(1-\beta)$ for detecting $5(\mathbf{A}), 10(\mathbf{B})$, and $20(\mathbf{C})$ percent difference in cell membrane thermostability (MTS) between differing number of clones screened in a randomized complete block design, when applying high temperature stress to immature leaves in a water bath set at $50{ }^{\circ} \mathrm{C}$ for 45 min. $\alpha$ of $0.05, \sigma_{\text {residual }}$ of 0.0438 , and $\sigma_{\text {block }}$ of 0.0873 were used in calculations. Tukey's honestly significant difference adjustment was applied to control for multiple testing error. Block number represents the number of complete blocks in experiment thus total number of plants $=$ block number $\times$ number of cultivars.

Srinivasan et al. (1996) reports both electrolyte leakage and CFL as successful in separating differences in high temperature tolerance among groundnut, soya bean (Glycine $\max$ L. Merr), chickpea, and pigeonpea (Cajanus cajan L. Millsp.). In contrast to our experiment, they found CFL a useful indicator of high temperature tolerance when subjecting both detached leaves and whole plants to high temperature stress. Srinivasan et al. (1996) only recorded MTS from leaf disks stressed in a water bath, although Camejo et al. (2005) reported a difference between two tomato lines measuring MTS on leaves when whole plants were stressed at $42{ }^{\circ} \mathrm{C}$ for $2 \mathrm{~h}$. The correlation $\left(r=0.74^{* * *}\right)$ between CFL and MTS from leaves stressed in the water bath was in line with those reported by Srinivasan et al. (1996) (0.570.87). In contrast to Srinivasan et al. (1996), we recorded CFL and MTS on the same leaves as opposed to different leaves on the same plant, which allows for a more direct comparison of the CFL and MTS.

Subjecting $\mathrm{BD}$ and $\mathrm{KO}$ to 2-week high temperature treatments $\left(36 / 28^{\circ} \mathrm{C}\right.$ day/night $)$ at different stages of flower development resulted in increased abscission when high temperature treatments were within 2 to 3 weeks of flowers opening, with BD being more susceptible to flower abscission than KO (Greyvenstein et al., 2014). Results from these experiments show that a short hightemperature shock at a sensitive stage of development (flower bud $2 \mathrm{~mm}$ in diameter) can increase flower abscission in susceptible clones. Evaluating the presence and absence of leaf necrosis 10-d post heat chamber treatment indicated that SC (poor field performer) was more sensitive to necrosis than J06B (good field performer). The reduction in flower size was not significantly different between J06A and SC, although a larger sample size will likely increase the precision of the test. Flower abscission and leaf necrosis $10 \mathrm{~d}$ post heat chamber treatment appear to be better indicators of high temperature susceptibility than flower size.

Lower electrolyte leakage in J06B compared with VS after subjecting 10 replicates to high temperature stress in the water bath acted as proof of concept for the method presented. Using a water bath stress and measuring MTS may separate clones based on field performance such as the J06 clones vs. VS and SC.
Power analyses are used prospectively in planning future studies and determining sample sizes required. Our power analyses predicted that differences in MTS greater than 0.1 would consistently be detected between clones with fairly small replications, although the number of replications would have to be adjusted depending on the number of clones to be compared.

\section{Conclusion}

A series of concomitant experiments indicated that MTS was a more sensitive indicator of susceptibility to high temperature stress in garden roses than CFL. The results supported the use of immature leaves over mature leaves in phenotyping high temperature susceptibility. When plants were stressed at $44^{\circ} \mathrm{C}$ for $3 \mathrm{~h}$ in the heat chamber, CFL was not significantly affected, only MTS was able to detect differences between clones. Subjecting immature leaves to stress in a water bath at $50{ }^{\circ} \mathrm{C}$ for $45 \mathrm{~min}$ resulted in both CFL and MTS being able to separate differences between clones. MTS was able to detect differences between clones when mature leaves were stressed in a water bath, whereas CFL could not.

Overall landscape performance ratings do not necessarily reflect high temperature susceptibility. Landscape performance is affected by any number of factors and some clones with poor landscape ratings can show adaptation for high temperature tolerance. However, it is unlikely that a laboratory test will ever completely replace field evaluation when selecting for adaptation to abiotic stress factors. Combining MTS from immature leaves stressed in a water bath with flower abscission and leaf necrosis after a high temperature shock in a heat chamber could be used in breeding programs to select against the most susceptible plants, resulting in more efficient use of land for evaluating new material in the field.

\section{Literature Cited}

Aggie Horticulture. 2013. Texas AgriLife Extension Service. Earth-Kind Roses. 31 Aug. 2013. <http:// aggie-horticulture.tamu.edu/earthkindroses/>.

Aggie Horticulture. 2014. Texas A\&M Rose Breeding and Genetics Program. 2 Jan. 2014. $<$ http://aggie-horticulture.tamu.edu/rose/>.
Berry, J. and O. Björkman. 1980. Photosynthetic response and adaptation to temperature in higher plants. Annu. Rev. Plant Physiol. 31:491-543.

Bilger, H.W., U. Schreiber, and O. Lange. 1984. Determination of leaf heat resistance: Comparative investigation of chlorophyll fluorescence changes and tissue necrosis methods. Oecologia 63:256-262.

Björkman, O. and B. Demmig. 1987. Photon yield of $\mathrm{O}_{2}$ evolution and chlorophyll fluorescence characteristics at $77 \mathrm{~K}$ among vascular plants of diverse origins. Planta 170:489-504.

Bravo, R.M. 2009. Genetic and quantitative analysis of red raspberry (Rubus idaeus) for heat tolerance and longer chilling requirement. NC. State Univ., Raleigh, PhD Diss.

Bruun, H.H. 2005. Rosa rugosa Thunb. ex Murray. J. Ecol. 93:441-470.

Byrne, D.H., N. Anderson, M. Orwat, and V. Soules. 2010. Field assessment of black spot resistance in roses in a hot humid climate. Acta Hort. 870:115-120.

Camejo, D., P. Rodríguez, M. Angeles Morales, J. Miguel Dell'Amico, A. Torrecillas, and J.J. Alarcón. 2005. High temperature effects on photosynthetic activity of two tomato cultivars with different heat susceptibility. J. Plant Physiol. 162:281-289.

Dela, G., E. Or, R. Ovadia, A. Nissim-Levi, D. Weiss, and M. Oren-Shamir. 2003. Changes in anthocyanin concentration and composition in 'Jaguar' rose flowers due to transient high-temperature conditions. Plant Sci. 164:333-340.

Fernandez, G.E. and M.P. Pritts. 1994. Growth, carbon acquisition, and source-sink relationships in 'Titan' red raspberry. J. Amer. Soc. Hort. Sci. 119:1163-1168.

Greyvenstein, O., B. Pemberton, T. Starman, G. Niu, and D. Byrne. 2014. Effect of two-week high-temperature treatment on flower quality and abscission of Rosa L. 'Belinda's Dream' and 'RADrazz' (KnockOut ${ }^{\circledR}$ ) under controlled growing environments. HortScience 49:701705.

Hakam, N., J.R. DeEll, S. Khanizadeh, and C. Richer. 2000. Assessing chilling tolerance in roses using chlorophyll fluorescence. HortScience 35:184-186.

HelpMeFind. 2012. HelpMeFind Roses, clematis, and peonies. 15 Nov. 2012. <http://www.helpmefind. com/rose/l.php?1=2.5791>

Hutton, S. 2012. The future of the rose industry. American Rose 41:36-37.

Ibrahim, A.M.H. and J.S. Quick. 2001a. Genetic control of high temperature tolerance in wheat as measured by membrane thermal stability. Crop Sci. 41:1405-1407.

Ibrahim, A.M.H. and J.S. Quick. 2001b. Heritability of heat tolerance in winter and spring wheat. Crop Sci. 41:1401-1405. 
Krause, G.H. and E. Weis. 1991. Chlorophyll fluorescence and photosynthesis: The basics. Annu. Rev. Plant Biol. 42:313-349.

Kuo, C., B. Shen, H. Chen, H. Chen, and R. Opena. 1988. Associations between heat tolerance, water consumption, and morphological characters in Chinese cabbage. Euphytica 39:65-73.

Kuo, C.G., H.M. Chen, and H.C. Sun. 1993. Membrane thermostability and heat tolerance of vegetable leaves, p. 160-168. In C.G. Kuo (ed.). Adaptation of food crops to temperature and water stress. Asian Veg. Res. Dev. Center, Shanhua, Taiwan.

Lenth, R.V. 2006. Java applets for power and sample size. Jan 2013. <http://www.stat. uiowa.edu/ $\sim$ rlenth/Power $>$.

Lenth, R.V. 2007. Statistical power calculations. J. Anim. Sci. 85:E24-E29.

Mackay, W.A., S.W. George, C. McKenney, J.J. Sloan, R.I. Cabrera, J.A. Reinert, P. Colbaugh, L. Lockett, and W. Crow. 2008. Performance of garden roses in North-central Texas under minimal input conditions. HortTechnology 18:417-422.
Marissen, N. 2001. Effects of pre-harvest light intensity and temperature on carbohydrate levels and vase life of cut roses. Acta Hort. 543:331-343.

Moe, R. 1975. The effect of growing temperature on the keeping quality of cut roses. Acta Hort. 41:77-93.

Sachs, J. 1864. Üeber die obere TemperaturGränze der Vegetation. Flora 47:5-12, 24-29, 33-39, 65-75.

Shin, H.K., J.H. Lieth, and S.H. Kim. 2001. Effects of temperature on leaf area and flower size in rose. Acta Hort. 547:185-191.

Srinivasan, A., H. Takeda, and T. Senboku. 1996. Heat tolerance in food legumes as evaluated by cell membrane thermostability and chlorophyll fluorescence techniques. Euphytica 88:35-45.

Stoddard, F.L., C. Balko, W. Erskine, H.R. Khan, W. Link, and A. Sarker. 2006. Screening techniques and sources of resistance to abiotic stresses in cool-season food legumes. Euphytica 147:167-186
Thiaw, S. and A.E. Hall. 2004. Comparison of selection for either leaf-electrolyte-leakage or pod set in enhancing heat tolerance and grain yield of cowpea. Field Crops Res. 86:239-253.

Wahid, A., S. Gelani, M. Ashraf, and M.R. Foolad. 2007. Heat tolerance in plants: An overview. Environ. Exp. Bot. 61:199-223.

Wang, C.H., D.M. Yeh, and C.S. Sheu. 2008. Heat tolerance and flowering-heat-delay sensitivity in relation to cell membrane thermostability in Chrysanthemum. J. Amer. Soc. Hort. Sci. 133:754-759.

Weng, J.H. and M.F. Lai. 2005. Estimating heat tolerance among plant species by two chlorophyll fluorescence parameters. Photosynthetica 43:439-444.

Yamada, M., T. Hidaka, and H. Fukamachi. 1996. Heat tolerance in leaves of tropical fruit crops as measured by chlorophyll fluorescence. Sci. Hort. 67:39-48.

Yeh, D.M. and H.F. Lin. 2003. Thermostability of cell membranes as a measure of heat tolerance and relationship to flowering delay in chrysanthemum. J. Amer. Soc. Hort. Sci. 128:656-660. 